\title{
Simple and Fast Load Flow Solution for Electrical Power Distribution Systems
}

\author{
T. Ramana ${ }^{1}$, V. Ganesh ${ }^{2}$, and S. Sivanagaraju ${ }^{3}$ \\ ${ }^{1}$ HP Global Soft Limited, Bangalore, Karnataka, India \\ ${ }^{2}$ JNTUCE, Dept. of Electrical and Electronics Engg., Pulivendula, Andhra Pradesh, India \\ ${ }^{3}$ JNTUCE, Dept. of Electrical and Electronics Engg., Kakinada, Andhra Pradesh, India \\ tramady@yahoo.co.in, gani_vg@yahoo.com, sirigiri70@yahoo.co.in
}

\begin{abstract}
The proposal of this paper is on a simple and fast distribution load flow solution algorithm. The proposed method fully exploits the radial structure of the network and solves the distribution load flow directly using the single dimension vectors. An effective data structure is proposed to identify lines and number of lines available beyond the particular line. Using this concept, power summations are calculated to obtain the distribution load flow solution. Unlike other traditional methods, the proposed method consider the effective convergence approach which is not only simple and fast but also is efficient from time perspective and needs very less memory for any size of the distribution system compared with the existing methods. The proposed concept was tested on standard distribution system and results are promising and have great potential for applications in the distribution automation.
\end{abstract}

Keywords: Load flow solution, line path identification, sparse technique, distribution automation, distribution systems

\section{Introduction}

There are many solution techniques for load flow calculations. However, an acceptable load flow method should meet the requirements [1] such as high speed and low storage requirements, highly reliable, and accepted versatility and simplicity.

In fact, conventional load flow methods, which were developed to solve the transmission networks, encounter convergence problems when applied to distribution networks due to high $\mathrm{R} / \mathrm{X}$ ratio. In view of the topological specialty of distribution networks, and non-applicability of the transmission networks power flows, researchers has proposed several special load flow techniques for distribution networks [2-8]. The methods [2-8] derive quadratic equations that relate the sending and receiving end voltage magnitudes with a strong convergence characteristic and speed. However, these solution procedures depend on the knowledge of the distribution system structure.

The methods [9-11] have presented power flow problem of distribution systems in terms of sets of recursive equations and analyzed power flow results for various voltage dependent load models. D. Das et al. $[12,13]$ have presented proposed a simple algebraic recursive expression of voltage magnitude and the proposed algorithm uses the basic principle of the circuit theory. J.Liu et al. [14] have proposed Ratio-Flow method based on forward-backward ladder equation for complex distribution system by using voltage ratio for convergence control. B. Venkatesh and R. Ranjan [15] have shown th ability of automation algorithms to handle these complex tasks that require frequent topology changes in the RDS demands a dynamic topology processor based on a well-defined data structure.

J. H. Teng [16] has proposed a direct approach by using the topological characteristics of the distribution networks to solve the power flow problem. A. Dimitrovski and K. Tomsovic [17] have presented a boundary power flow solution, which considers the uncertainty in nodal powers as boundary values. Jabr [18] has formulated the distribution load flow problem as

Received: December $30^{\text {th }}$, 2012. Accepted: July 26 ${ }^{\text {th }}$, 2013 
Conic Programming based Convex Optimization Problem. Hamounda and Zeher [19] have proposed a distribution load flow based on Kirchhoff's laws characterized by radial configuration and laterals. Jamali et al. [20] presented a load-flow technique based on sequential branch numbering scheme to design distribution network by considering committed loads.

Singh, et. al. [21] presented a load flow solution for radial and weakly meshed distribution system formulated as an optimization problem solved by Primal dual Interior point method. The methods [22-23] have proposed an algebraic trigonometric recursive expression of voltage magnitude and the proposed algorithm using the spare technique. The proposed spare technique will fail when bus numbering is not in proper order. Abul Wafa [24] has proposed a based on the two elements sparse S matrix and solve the voltage expression for the receiving end voltage using the composite loads.

The aim paper is to propose a simple and fast load flow method for distribution systems. A method is presented for identifying the line paths beyond a particular line using sparse technique, which will improve the speed of the proposed method. Load flow solution is based on simple iterative method of receiving end voltage of radial distribution system. The convergence of the method is accelerated by a judicious choice of the initial voltages and power losses are taken into consideration from the first iteration. The proposed method is tested on standard distribution systems, and then it is compared with the results of seven existing methods.

\section{Formulation of proposed single dimension matrices}

A. Line Identification Scheme

Table 1. Formation of pln[ ] matrix

\begin{tabular}{|c|c|c|}
\hline S.No.[s] & $\operatorname{pln}[\mathrm{s}]$ & Line No. \\
\hline 1 & 1 & \multirow{8}{*}{1} \\
\hline 2 & 2 & \\
\hline 3 & 3 & \\
\hline 4 & 5 & \\
\hline 5 & 4 & \\
\hline 6 & 7 & \\
\hline 7 & 6 & \\
\hline 8 & 8 & \\
\hline 9 & 2 & \multirow{7}{*}{2} \\
\hline 10 & 3 & \\
\hline 11 & 5 & \\
\hline 12 & 4 & \\
\hline 13 & 7 & \\
\hline 14 & 6 & \\
\hline 15 & 8 & \\
\hline 16 & 3 & \multirow{4}{*}{3} \\
\hline 17 & 4 & \\
\hline 18 & 7 & \\
\hline 19 & 8 & \\
\hline 20 & 4 & 4 \\
\hline 21 & 5 & \multirow{2}{*}{5} \\
\hline 22 & 6 & \\
\hline 23 & 6 & 6 \\
\hline 24 & 7 & \multirow{2}{*}{7} \\
\hline 25 & 8 & \\
\hline 26 & 8 & 8 \\
\hline
\end{tabular}


Table 2. Formation of ipf[ ] and ipt[ ] Matrices

\begin{tabular}{|c|c|c|}
\hline Line No. & ipf[i] & ipt[i] \\
\hline 1 & 1 & 8 \\
\hline 2 & 9 & 15 \\
\hline 3 & 16 & 19 \\
\hline 4 & 20 & 20 \\
\hline 5 & 21 & 22 \\
\hline 6 & 23 & 23 \\
\hline 7 & 24 & 25 \\
\hline 8 & 26 & 26 \\
\hline
\end{tabular}

For a multiphase balanced radial distribution system, the system tree is represented as a single line equivalent, where a line between two buses represents only the connectivity between the buses.

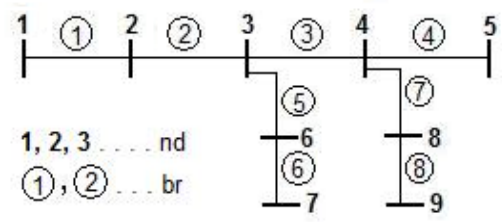

Figure 1. Sample Radial Distribution System

A single dimension vector, namely, path line vector $\operatorname{pln}[$ ] is introduced to store all the lines beyond the path including the path line which is interested. The dimension of the vector is changed based on the tree structure of the radial distribution system. Two other vectors ipathfrom, ipf[ ] and ipath-to, ipt[ ] are introduced which acts as points to the pln[ ] vector and whose dimensions are equal to the number of lines available in the radial distribution system. These vectors in turn govern the reservation allocation of memory location of each path line, where ipf[ ] and ipt[ ] hold the data of starting memory allocation and each memory location of path line $\mathrm{i}$ in the $\ln [\mathrm{]}$ vector, $\mathrm{i}=1,2, \ldots$ br. There is no dependence of the of buses numbering order with the substation bus number. The above mentioned branch identification scheme is explained with reference to a sample distribution system of Figure 2. Table 1 and Table 2 shows data stored in $\operatorname{pln}[$ ], ipf[ ] and ipt[ ] vectors of the sample distribution system. Figure 3 shows the flow chart for the formation of pln[ ], ipf[ ] and ipt[ ] vectors.

\section{B. Sparse Technique}

In the proposed sparse technique, single dimensional vectors are used instead of two dimensional arrays in Ghosh and Das method [12] for implementation. This can reduce a lot of memory and CPU time as it minimizes the search process in identifying the adjacent nodes and branches beyond a particular branch. With two dimensional arrays, a system with n nodes needs matrix size of $n \times n$. In which most of the elements are zero. This can be avoided by three single dimensional vectors ipf[br], ipt[br] and $\operatorname{pln}[\mathrm{br}(\mathrm{br}+1) / 2]$. The $\operatorname{pln}[\mathrm{l}]$ vector size is less than or equal to $\operatorname{br}(\mathrm{br}+1) / 2$ based on the radial distribution tree structure. The total elements/location of vectors is the $2 \times \mathrm{br}$ plus less than or equal to $1 \times \mathrm{br}(\mathrm{br}+1) / 2$ and they are very much less than $n \times n$ in [12]. Therefore proposed technique reduces the memory requirement and CPU time for large distribution systems. 


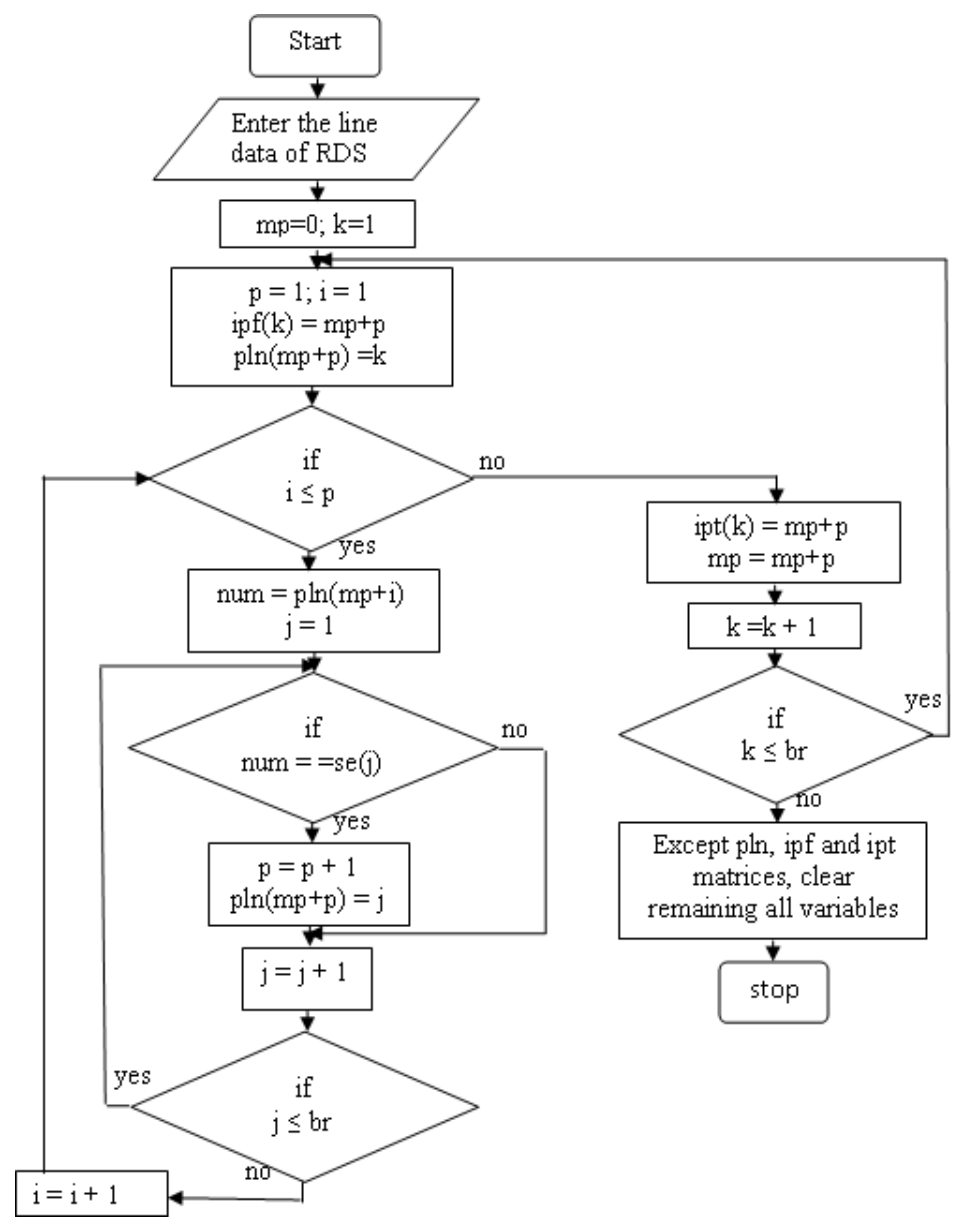

Figure 2. Flowchart for the formation of pln[ ], ipf[ ] and ipt[ ]

\section{Advantages of the Scheme}

a) There is no dependency of the order of node numbers like other methods [9-23].

b) An end bus can be easily identified.

c) For an branch i, where ipf[i] - ipt[i] = 0, then end bus is re(pln[ipf[i]]) or re(pln[ipt[i]]).

d) Applying the scheme, directly the backwards direction to calculate the power flows in the line and the forward direction to calculate voltages very fast and effective.

e) On application of this scheme, there is reduction of memory usage and CPU time as it minimizes the search process in identifying the adjacent buses and braches of a radial distribution system.

\section{Mathematical Formulation}

\section{A. Assumptions}

It is assumed that the three-phase radial distribution system is balanced and thus can be represented by its one line diagram. The loads are modeled as constant power. Distribution feeders are of medium level voltage then, the shunt capacitance are negligible.

\section{B. Mathematical models}

Consider an equivalent circuit model of typical branch between buses $\mathrm{p}$ and $\mathrm{q}$ of the radial distribution system as shown in Figure 2. In Figure 2, $|\mathrm{V}(\mathrm{p})| \angle \delta(\mathrm{p})$ and $|\mathrm{V}(\mathrm{q})| \angle \delta(\mathrm{q})$ are the voltage magnitudes and phase angles of two buses $\mathrm{p}$ and $\mathrm{q}$ respectively and power flowing 
through the line $p q$ is $P(p q)+j Q(p q)$ and $P_{1}(p q)+j Q_{1}(p q)$ at sending end and receiving end buses respectively. The substation voltage is assumed to be $(1+\mathrm{j} 0)$ p.u..

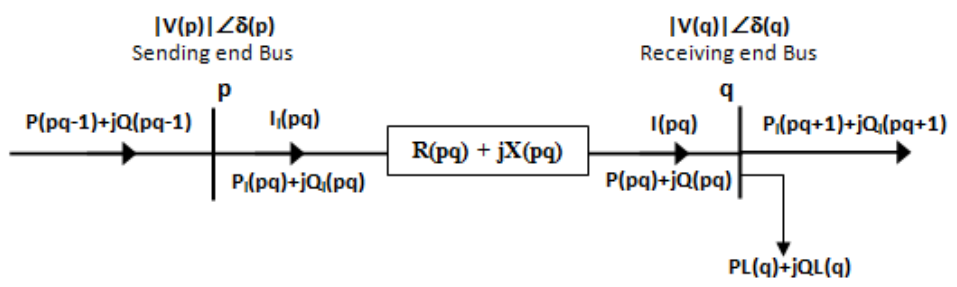

Figure 3. Equivalent circuit model of RDS of a typical branch $p q$

\section{B.1 Branch Power and Current}

From the electric equivalent of a feeder branch shown in Figure3, we can write the set of the below power summation equations for branch pq.

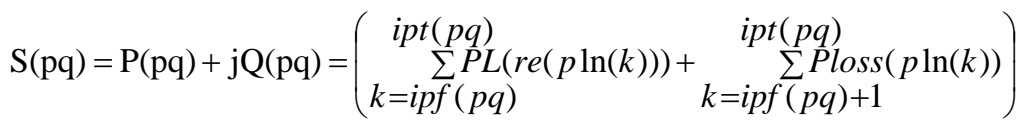

$$
\begin{aligned}
& +j\left(\sum_{k=i p f(p q)}^{i p t(p q)}(r e(p \ln (k)))+\underset{k=i p f(p q)+1}{i p t(p q)}\right. \\
& \mathrm{S}_{1}(\mathrm{pq})=\mathrm{P}_{\mathrm{l}}(\mathrm{pq})+\mathrm{jQ}_{\mathrm{l}}(\mathrm{pq})=(\mathrm{P}(\mathrm{pq})+\operatorname{Ploss}(\mathrm{pq}))+\mathrm{j}(\mathrm{Q}(\mathrm{pq})+\mathrm{Qloss}(\mathrm{pq}))
\end{aligned}
$$

where

$\mathrm{PL}(\mathrm{re}(\mathrm{pln}(\mathrm{k})))$ and $\mathrm{QL}(\mathrm{re}(\mathrm{p} \ln (\mathrm{k})))$ : active and reactive load power at path line $\mathrm{pln}(\mathrm{k})$ of receiving end bus respectively.

Ploss(pln(k)) and $\mathrm{Qloss}(\mathrm{pln}(\mathrm{k}))$ : active and reactive power loss in the path line $\operatorname{pln}(\mathrm{k})$ respectively.

$\mathrm{P}(\mathrm{pq})$ and $\mathrm{Q}(\mathrm{pq})$ : active and reactive power at the end of branch $p q$. It is equal to the sum of the active and reactive power of all the loads beyond bus q (bus q included) plus the sum of the active and reactive power losses of the branches beyond bus q (branch $p q$ not included) respectively.

$\mathrm{P}_{1}(\mathrm{pq})$ and $\mathrm{Q}_{1}(\mathrm{pq})$ : active and reactive power at the beginning of the branch $p q$. It is equal to the sum of the power at the end of branch $p q$ plus the active and reactive power loss in this same branch respectively.

Ploss(pq) and Qloss(pq) : active and reactive power loss in the branch $p q$ respectively.

If the complex voltage at the bus q,

$$
\mathrm{V}(\mathrm{q})=|V(q)|(\cos \delta(q)+j \sin \delta(q))
$$

Than, the current following through the ith branch with respect to receiving end voltage is

$$
\mathrm{I}(\mathrm{pq})=\left(\frac{S(p q)}{V(q)}\right)^{*}=\frac{P(p q)-j Q(p q)}{V(q)^{*}}
$$

and the current following through the ith branch with respect to sending end voltage is 


$$
\mathrm{I}_{1}(\mathrm{pq})=\left(\frac{S_{1}(p q)}{V(p)}\right)^{*}=\frac{P_{1}(p q)-j Q_{1}(p q)}{V(p)^{*}}
$$

The $p q^{\text {th }}$ branch active and reactive power losses are given by

$$
\operatorname{Sloss}(\mathrm{pq})=\operatorname{Ploss}(\mathrm{pq})+\mathrm{jQloss}(\mathrm{pq})=(I(p q))^{*} I(p q) \mathrm{Z}(p q)
$$

Where

$\mathrm{Z}(\mathrm{pq})$ : Impendance of the branch $p q$ and equal to $\mathrm{R}(\mathrm{pq})+\mathrm{jX}(\mathrm{pq})$

\section{B.2 Bus Voltage}

For computing the receiving voltage, we canwrite the following complex expression

$$
V(q)=V(p)-I_{1}(p q) Z(p q)
$$

\section{Flow Chart for Load Flow Calculation}

The initial voltage set the higher values compared to final ones, produce lower starting line current and low voltage drop. Thus, for a given line, the voltage of the receiving end bus is far from its actual value. The iterative process takes then, a great number of iterations and therefore a relatively long time to converge. In order to reduce the computing time and increase the convergence speed, a different the voltage calculation methodology proposed. The current

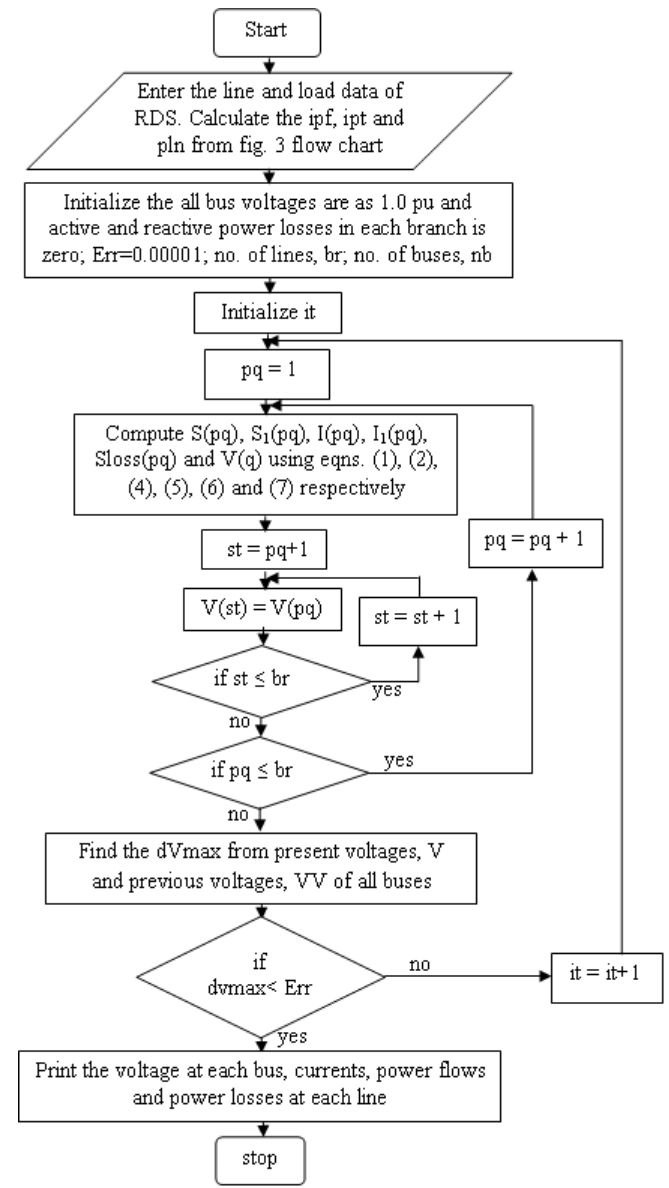

Figure 4. Flowchart for load flow calculation 
for a given line is equal to the sum of load required current at the buses to which they belong. Then, in the calculation of the receiving end bus voltage of a given branch, the loads currents are evaluated on the basis of the sending end voltage. In addition, both active and reactive power losses are introduced from the first iteration and calculated also on the basis of the considered line sending end voltage.

The convergence criterion of the proposed method is that if, in successive iterations the maximum difference is voltage magnitude (dVmax) is less than 0.0001 p.u., the solution have then converged. The complete load flow calculation flow chart for radial distribution system is shown in Figure 4.

\section{Results and Analysis}

To demonstrate the effectiveness of the proposed method, following three examples are selected. The first example is of a 15-bus, $11 \mathrm{kV}$ radial distribution system. The data of the system is available in [9]. The total real and reactive power loads at nominal voltage are $1226.40 \mathrm{~kW}$ and $1250.93 \mathrm{kVAr}$ respectively. The real and reactive power line losses are $5.04 \%$ and $4.58 \%$ of their respective real and reactive loads respectively. The minimum voltage of this system is at bus 12 and voltage regulation is $5.56 \%$. Table 3 gives the line numbers and voltage at receiving end with phase angle, injected power in each branch and losses of the line section between nodes for constant power load model only.

Table 3.The summary of load flow results for 15-bus RDS

\begin{tabular}{|c|c|c|c|c|c|c|c|c|c|c|}
\hline \multirow[b]{2}{*}{$\mathrm{Br}$} & \multirow[b]{2}{*}{$\mathrm{p}$} & \multirow[b]{2}{*}{$\mathrm{q}$} & \multirow{2}{*}{$\begin{array}{l}\text { Voltage } \\
\mathrm{V}_{\mathrm{q}} \text { (p.u) }\end{array}$} & \multirow{2}{*}{$\begin{array}{c}\text { Angle } \\
\delta_{\mathrm{q}}(\mathrm{rad})\end{array}$} & \multicolumn{4}{|c|}{ Injected Powers } & \multicolumn{2}{|c|}{ Power Losses } \\
\hline & & & & & $\mathrm{P}_{\mathrm{pq}}(\mathrm{kW})$ & $\mathrm{P}_{\mathrm{qp}}(\mathrm{kW})$ & $\begin{array}{c}\mathrm{Q}_{\mathrm{pq}} \\
(\mathrm{kVAr})\end{array}$ & $\begin{array}{c}\mathrm{Q}_{\mathrm{qp}} \\
\text { (kVAr) }\end{array}$ & $\begin{array}{l}\text { Ploss } \\
(\mathrm{kW})\end{array}$ & $\begin{array}{c}\text { Qloss } \\
\text { (kVAr) }\end{array}$ \\
\hline 1 & 1 & 2 & 0.97128 & 0.00056 & 1288.17 & 1250.48 & 1308.46 & 1271.58 & 37.70 & 36.88 \\
\hline 2 & 2 & 3 & 0.95689 & 0.00086 & 724.27 & 712.99 & 747.61 & 726.58 & 11.28 & 11.03 \\
\hline 3 & 3 & 4 & 0.95117 & 0.00099 & 394.81 & 392.37 & 402.56 & 400.17 & 2.44 & 2.39 \\
\hline 4 & 4 & 5 & 0.95018 & 0.00120 & 44.10 & 44.04 & 44.99 & 44.95 & 0.06 & 0.04 \\
\hline 5 & 2 & 6 & 0.95813 & 0.00336 & 358.44 & 352.67 & 365.06 & 361.17 & 5.77 & 3.89 \\
\hline 6 & 6 & 7 & 0.95591 & 0.00383 & 140.00 & 139.61 & 142.83 & 142.56 & 0.39 & 0.27 \\
\hline 7 & 6 & 8 & 0.95685 & 0.00363 & 70.19 & 70.08 & 71.55 & 71.47 & 0.11 & 0.08 \\
\hline 8 & 2 & 9 & 0.96793 & 0.00126 & 116.23 & 115.76 & 117.84 & 117.52 & 0.47 & 0.32 \\
\hline 9 & 9 & 10 & 0.96686 & 0.00148 & 44.10 & 44.04 & 44.99 & 44.95 & 0.06 & 0.04 \\
\hline 10 & 3 & 11 & 0.95030 & 0.00228 & 252.35 & 250.18 & 256.89 & 255.42 & 2.17 & 1.47 \\
\hline 11 & 11 & 12 & 0.94619 & 0.00316 & 114.18 & 113.58 & 116.46 & 116.05 & 0.60 & 0.41 \\
\hline 12 & 12 & 13 & 0.94488 & 0.00345 & 44.10 & 44.03 & 44.99 & 44.94 & 0.07 & 0.05 \\
\hline 13 & 4 & 14 & 0.94886 & 0.00148 & 70.64 & 70.44 & 71.72 & 71.58 & 0.20 & 0.14 \\
\hline 14 & 4 & 15 & 0.94870 & 0.00152 & 140.41 & 139.97 & 143.11 & 142.81 & 0.44 & 0.30 \\
\hline
\end{tabular}

The second example is a 33-bus, $12.66 \mathrm{kV}$ radial distribution system. Data for this system is available [14]. The total real and reactive power loads at nominal voltage are $3715 \mathrm{~kW}$ and $2300 \mathrm{kVAr}$, respectively. The real and reactive power line losses are $5.64 \%$ and $6.18 \%$ of their respective real and reactive loads, respectively. The minimum voltage of this system is at bus 18 and voltage regulation is $9.49 \%$. The load flow solution bus voltages and phase angles results for 33-bus RDS has been shown in Table 4. The proposed method was also implemented for various ratios $\mathrm{R} / \mathrm{X}$ for a tolerance of $10^{-4}$ p.u., the solution is reached after two iteration for the considered values of $\mathrm{R} / \mathrm{X}$. The solution results of minimum voltage and number of iterations are shown in Table 5 for the considered values of $\mathrm{R} / \mathrm{X}$. The bus voltages evolution according to $\mathrm{R} / \mathrm{X}$ is in conformity with the electric circuit laws. For the same line current, low voltage drop is due to reactance.

The third example is a 69-node, $12.66 \mathrm{kV}$ radial distribution network. Data for this system is available [3]. The total real and reactive power loads at nominal voltage are $3791.89 \mathrm{~kW}$ and $2694.10 \mathrm{kVAr}$ respectively. The losses are $5.89 \%$ and $3.76 \%$ of their respective real and reactive loads respectively. The minimum voltage of this system is at bus 65 and voltage regulation is $8.94 \%$. The load flow solution bus voltages and phase angles results for 69-bus RDS has been shown in Table 6. Various load conditions are also considered by multiplying 
each bus acitive and reactive powers by a constant. For the 69-bus system and for the considered load factors, the number of iterations to reach the convergence is two for a convergence rate of $10^{-4} \mathrm{p}$.u. The solution results of minimum voltage and number of iterations are shown in Table 7 for the considered values of loading factors. However, we note a constant voltage at some buses regardless the load conditions. This could be explained by the fact that, these buses are close to the source bus, the loads low level and the small values of the branch parameters.

Table 4. Load Flow solution bus voltages and phase angles for 33-bus RDS

\begin{tabular}{|c|c|c|c|c|c|c|c|c|}
\hline $\begin{array}{c}\text { Bus } \\
\text { No }\end{array}$ & $\begin{array}{c}\text { Voltage } \\
\text { in p.u. }\end{array}$ & $\begin{array}{c}\text { Angle } \\
\text { in p.u. }\end{array}$ & $\begin{array}{c}\text { Bus } \\
\text { No }\end{array}$ & $\begin{array}{c}\text { Voltage } \\
\text { in p.u. }\end{array}$ & $\begin{array}{c}\text { Angle } \\
\text { in p.u. }\end{array}$ & $\begin{array}{c}\text { Bus } \\
\text { No }\end{array}$ & $\begin{array}{c}\text { Voltage } \\
\text { in p.u. }\end{array}$ & $\begin{array}{c}\text { Angle } \\
\text { in p.u. }\end{array}$ \\
\hline 1 & 1.00000 & 0.00000 & 12 & 0.91894 & -0.00646 & 23 & 0.97960 & 0.00114 \\
\hline 2 & 0.99702 & 0.00024 & 13 & 0.91282 & -0.00808 & 24 & 0.97298 & -0.00041 \\
\hline 3 & 0.98315 & 0.00166 & 14 & 0.91054 & -0.00948 & 25 & 0.96967 & -0.00117 \\
\hline 4 & 0.97573 & 0.00281 & 15 & 0.90912 & -0.01015 & 26 & 0.94844 & 0.00301 \\
\hline 5 & 0.96839 & 0.00397 & 16 & 0.90774 & -0.01056 & 27 & 0.94589 & 0.00399 \\
\hline 6 & 0.95032 & 0.00233 & 17 & 0.90570 & -0.01193 & 28 & 0.93461 & 0.00544 \\
\hline 7 & 0.94683 & -0.00170 & 18 & 0.90509 & -0.01210 & 29 & 0.92647 & 0.00679 \\
\hline 8 & 0.93341 & -0.00437 & 19 & 0.99643 & 0.00004 & 30 & 0.92293 & 0.00863 \\
\hline 9 & 0.92713 & -0.00567 & 20 & 0.99287 & -0.00113 & 31 & 0.91880 & 0.00716 \\
\hline 10 & 0.92132 & -0.00679 & 21 & 0.99216 & -0.00147 & 32 & 0.91788 & 0.00675 \\
\hline 11 & 0.92045 & -0.00666 & 22 & 0.99153 & -0.00183 & 33 & 0.91760 & 0.00662 \\
\hline
\end{tabular}

Table 5. Minimum Voltages and number of iterations for different R/X ratios for 33-bus RDS

\begin{tabular}{|c|c|c|}
\hline \multicolumn{3}{|c|}{ Convergence rate is $10^{-4}$ p.u. } \\
\hline R/X ratio & $\begin{array}{c}\text { Minimum } \\
\text { Voltage }\end{array}$ & $\begin{array}{c}\text { Number of } \\
\text { Iteration }\end{array}$ \\
\hline Base case & 0.90509 & 2 \\
5 & 0.85625 & 2 \\
7.5 & 0.78692 & 2 \\
10 & 0.70573 & 2 \\
\hline
\end{tabular}

Table 6. Load Flow solution bus voltages and phase angles for 69-bus RDS

\begin{tabular}{|l|l|l|l|l|l|l|l|l|}
\hline $\begin{array}{l}\text { Bus } \\
\text { No }\end{array}$ & $\begin{array}{l}\text { Voltage } \\
\text { in p.u. }\end{array}$ & $\begin{array}{l}\text { Angle } \\
\text { in p.u. }\end{array}$ & $\begin{array}{l}\text { Bus } \\
\text { No }\end{array}$ & $\begin{array}{l}\text { Voltage } \\
\text { in p.u. }\end{array}$ & $\begin{array}{l}\text { Angle } \\
\text { in p.u. }\end{array}$ & $\begin{array}{l}\text { Bus } \\
\text { No }\end{array}$ & $\begin{array}{l}\text { Voltage } \\
\text { in p.u. }\end{array}$ & $\begin{array}{l}\text { Angle } \\
\text { in p.u. }\end{array}$ \\
\hline 1 & 1.00000 & 0.00000 & 24 & 0.95697 & 0.00860 & 47 & 0.99979 & -0.00013 \\
\hline 2 & 0.99997 & -0.00002 & 25 & 0.95681 & 0.00865 & 48 & 0.99855 & -0.00092 \\
\hline 3 & 0.99993 & -0.00004 & 26 & 0.95674 & 0.00867 & 49 & 0.99472 & -0.00334 \\
\hline 4 & 0.99984 & -0.00010 & 27 & 0.95672 & 0.00868 & 50 & 0.99418 & -0.00369 \\
\hline 5 & 0.99903 & -0.00032 & 28 & 0.99993 & -0.00005 & 51 & 0.97883 & 0.00243 \\
\hline 6 & 0.99023 & 0.00087 & 29 & 0.99986 & -0.00008 & 52 & 0.97882 & 0.00243 \\
\hline 7 & 0.98107 & 0.00213 & 30 & 0.99976 & -0.00004 & 53 & 0.97498 & 0.00296 \\
\hline 8 & 0.97887 & 0.00243 & 31 & 0.99975 & -0.00003 & 54 & 0.97177 & 0.00341 \\
\hline 9 & 0.97774 & 0.00258 & 32 & 0.99966 & 0.00001 & 55 & 0.96734 & 0.00404 \\
\hline 10 & 0.97277 & 0.00406 & 33 & 0.99946 & 0.00011 & 56 & 0.96301 & 0.00465 \\
\hline 11 & 0.97167 & 0.00439 & 34 & 0.99923 & 0.00024 & 57 & 0.94117 & 0.01156 \\
\hline 12 & 0.96853 & 0.00530 & 35 & 0.99916 & 0.00026 & 58 & 0.93028 & 0.01508 \\
\hline 13 & 0.96562 & 0.00611 & 36 & 0.99992 & -0.00005 & 59 & 0.92603 & 0.01649 \\
\hline 14 & 0.96273 & 0.00692 & 37 & 0.99975 & -0.00016 & 60 & 0.92104 & 0.01831 \\
\hline 15 & 0.95987 & 0.00772 & 38 & 0.99959 & -0.00021 & 61 & 0.91372 & 0.01951 \\
\hline 16 & 0.95934 & 0.00787 & 39 & 0.99954 & -0.00022 & 62 & 0.91343 & 0.01956 \\
\hline 17 & 0.95846 & 0.00812 & 40 & 0.99954 & -0.00022 & 63 & 0.91304 & 0.01962 \\
\hline 18 & 0.95845 & 0.00812 & 41 & 0.99884 & -0.00041 & 64 & 0.91115 & 0.01993 \\
\hline 19 & 0.95799 & 0.00827 & 42 & 0.99855 & -0.00049 & 65 & 0.91057 & 0.02003 \\
\hline 20 & 0.95769 & 0.00837 & 43 & 0.99851 & -0.00050 & 66 & 0.97161 & 0.00441 \\
\hline 21 & 0.95721 & 0.00852 & 44 & 0.99850 & -0.00050 & 67 & 0.97161 & 0.00441 \\
\hline 22 & 0.95720 & 0.00852 & 45 & 0.99841 & -0.00054 & 68 & 0.96820 & 0.00541 \\
\hline 23 & 0.95713 & 0.00855 & 46 & 0.99841 & -0.00054 & 69 & 0.96820 & 0.00541 \\
\hline
\end{tabular}


Table 7. Minimum Voltages and number of iterations for different loading factors for 69-bus RDS

\begin{tabular}{|c|c|c|}
\hline \multicolumn{3}{|c|}{ Convergence rate is $10^{-4}$ p.u. } \\
\hline $\begin{array}{c}\text { Loading } \\
\text { factor }\end{array}$ & Minimum Voltage & $\begin{array}{c}\text { Iteration } \\
\text { number }\end{array}$ \\
\hline 0.5 & 0.95695 & 2 \\
1.0 & 0.91057 & 2 \\
1.5 & 0.86013 & 2 \\
2.0 & 0.80454 & 2 \\
2.5 & 0.74219 & 2 \\
3.0 & 0.67035 & 2 \\
\hline
\end{tabular}

\section{A. Discussion and observations}

The results of proposed method implemented for the different convergence rates and it is observed that the number of iterations is equal to two and threefor the convergence rates $10^{-4}$ p.u. and $10^{-7}$ p.u. respectively. The minimum voltage, total real power losses, total reactive power losses of the system, number of iterations corresponding to the convergence rate is shown in Table 8.

Table 8. Summary of example RDS load flow results for different convergence rates

\begin{tabular}{|c|c|c|c|c|c|c|c|c|}
\hline \multirow[b]{2}{*}{$\begin{array}{c}\text { Example } \\
\text { RDS }\end{array}$} & \multicolumn{4}{|c|}{ Convergence rate is $10^{-4}$ p.u. } & \multicolumn{4}{|c|}{ Convergence rate is $10^{-7}$ p.u. } \\
\hline & $\begin{array}{l}\text { Vmin } \\
\text { in p.u. }\end{array}$ & $\begin{array}{l}\text { Total } \\
\text { Ploss in } \\
\text { kW }\end{array}$ & $\begin{array}{l}\text { Total } \\
\text { Qloss in } \\
\text { kVAr }\end{array}$ & $\begin{array}{c}\text { Iteration } \\
\text { number }\end{array}$ & $\begin{array}{l}\text { Vmin in } \\
\text { p.u. }\end{array}$ & $\begin{array}{l}\text { Total } \\
\text { Ploss in } \\
\text { kW }\end{array}$ & $\begin{array}{c}\text { Total } \\
\text { Qloss in } \\
\text { kVAr }\end{array}$ & $\begin{array}{l}\text { Iteration } \\
\text { number }\end{array}$ \\
\hline 15-Bus RDS & 0.94488 & 61.78 & 57.28 & 2 & 0.94488370 & 61.78 & 57.28 & 3 \\
\hline 33-Bus RDS & 0.90509 & 209.68 & 142.20 & 2 & 9050856 & 209.68 & 142.20 & 3 \\
\hline 69-Bus RDS & 0.91057 & 223.31 & 101.38 & 2 & 0.9105744 & 223.31 & 101.38 & 3 \\
\hline
\end{tabular}

Table 9. Comparison of speed and number of iteration of proposed method and existing methods with the convergence criteria of $10^{-4}$

\begin{tabular}{|l|c|c|c|c|c|c|}
\hline \multirow{2}{*}{\begin{tabular}{c} 
Proposed method $\begin{array}{c}\text { Pnother seven } \\
\text { existingmethods }\end{array}$ \\
\cline { 2 - 7 }
\end{tabular}} & $\begin{array}{c}\text { CPU time } \\
\text { (sec) }\end{array}$ & $\begin{array}{c}\text { Iteration } \\
\text { number }\end{array}$ & $\begin{array}{c}\text { CPU time } \\
\text { (sec) }\end{array}$ & $\begin{array}{c}\text { Iteration } \\
\text { number }\end{array}$ & $\begin{array}{c}\text { CPU time } \\
\text { (sec) }\end{array}$ & $\begin{array}{c}\text { Iteration } \\
\text { number }\end{array}$ \\
\hline Proposed method & 0.025 & 2 & 0.053 & 2 & 0.096 & 2 \\
Nagaraju et.al. [19] & 0.03 & 3 & 0.06 & 3 & 0.13 & 3 \\
Satynarayana et.al. [18] & 0.03 & 3 & 0.06 & 3 & 0.13 & 3 \\
Ghosh and Das [12] & 0.04 & 3 & 0.09 & 3 & 0.16 & 3 \\
Chaing [5] & 0.05 & 3 & 0.11 & 3 & 0.24 & 3 \\
Baran and Wu [3] & 0.07 & 3 & 0.13 & 3 & 0.29 & 3 \\
Renato method [6] & 0.08 & 4 & 0.14 & 4 & 0.33 & 4 \\
Kersting [2] & 0.10 & 4 & 0.16 & 4 & 0.37 & 4 \\
AbulWafa [24] & 0.11 & 4 & 0.14 & 4 & 0.16 & 4 \\
\hline
\end{tabular}

The proposed method is also compared with seven other existing methods for constant power load model. Table 9 gives the CPU time and number of iterations of all the three case studies. From Table 9, it is seen that the proposed method is better than the other seven existing methods. It can be concluded that the proposed method is robust and time efficient for the radial distribution systems and it can be said the proposed method has faster convergence ability than the other seven existing methods. The methods are implemented on Intel - i3, 1 GB-RAM processor.

\section{Conclusion}

In this paper, a simple and fast load flow solution algorithm for distribution system was proposed, which is basically a power summation method. The proposed scheme of line identification makes the method quite fast. This scheme reduces a lot of memory and CPU time 
as it minimizes the search process in the radial distribution system. The convergence of the method is accelerated by a judicious choice of the initial voltages and power losses are taken into consideration from the first iteration. Load flow problem under different load conditions and for various ratios $\mathrm{R} / \mathrm{X}$ has been successfully treated by out method. In order to test results, confirmation of the accuracy of the method is there, whereas the fastness of the both in terms of number of iterations and CPU execution time is evident from the results and finds great potential application in the distribution automation.

\section{Reference}

[1] B. Scott, "Review of load flow calculation methods," Proc. IEEE, Vol.62, No.7, pp. 916929, July 1974.

[2] W. H. Kersting, "A method to teach the design and operation of a distribution system", IEEE Trans. Power App. Syst., Vol.103, No.7, pp. 1945-1952, July 1984.

[3] M.E. Baran, F.F. Wu, "Optimal sizing of capacitors placed on a radial distribution system,” IEEE Trans. Power Deliv., Vol.4, No.1, pp. 735-743, 1989.

[4] S.K. Goswami, S. K. Basu, "Direct solution of distribution system," IEE Proc. C, Vol.188, No.1, pp.78-88, 1991.

[5] H.D. Chiang, "A decoupled load flow-method for distribution power networks: algorithms, analysis and convergence study," Elec. Power Energy Syst., Vol.13, No.3, pp.130-138, 1991.

[6] G. Renato Cespedes, "New method for the analysis of distribution networks," IEEE Trans. Power Delivery, Vol.5, No.1, pp.391-396, 1990.

[7] D. Das, H. S. Nagi, D. P. Kothari, "Novel method for solving radial distribution networks,” IEE Proc C, Vol.141, No.4, pp. 291-298, 1994.

[8] G.B. Jasmon, L.H.C. Lee, "Distribution network reduction for voltage stability analysis and load flow calculations,” Elec. Power Energy Syst., Vol.13, No. 1, pp. 9-13, 1991.

[9] D. Das, D.P. Kothari, A. Kalam, "Simple and efficient method for load flow solution of radial distribution networks,” Elec. Power Energy Syst., Vol17, No.5, pp. 335-346, 1995.

[10] M.H. Haque, "Load flow-solution of distribution systems with voltage dependent load models,” Elec. Power Syst. Res., Vol.36, pp. 151-156, 1996.

[11] S. Mok, S. Elangovan, C. Longjian, M. Salama, "A new approach for power-flow analysis of balanced radial distribution systems," Electric Machines Power Syst., Vol.28, pp.325-340, 2000.

[12] S. Ghosh, D. Das, "Method for load solution of radial distribution networks", IEE Proc. Gener. Transm. Distrib., Vol.146, No.6, pp. 641-648, 1999.

[13] R. Ranjan, D. Das, "Simple, Efficient computer algorithm to solve radial distribution networks”, Electric Power Comp. Syst., Vol.31, pp. 95-107, 2002.

[14] J. Liu, M.M.A. Salama, R.R. Mansour, "An efficient power-flow algorithm for distribution systems with polynomial load”, Int. J. Elec. Eng. Edu., Vol.39, No.4, pp. 372-386, 2002.

[15] B. Venkatesh, R. Ranjan, "Data structure for radial distribution system load flow analysis”, IEE Proc. Gener. Transm. Distrib, Vol.150, No.1, pp. 101-106, 2003.

[16] J.H. Teng, "A direct approach for distribution system load flow solution”, IEEE Trans. Power Del., Vol. 18, No. 3, pp. 882-887, Jul. 2003.

[17] A. Dimitrovski and K. Tomsovic, "Boundary power flow solutions", IEEE Trans. Power Syst., Vol. 19, No. 1, pp. 348-355, Feb. 2004.

[18] R.A. Jabr, "Radial distribution load flow using conic programming", IEEE Trans. on Power Syst., Vol. 21, No. 3, pp. 1458-1459, Aug. 2006.

[19] A. Hamouda and K. Zehar, "Efficient load flow method for radial distribution feeders", Journal of Applied Sciences, vol. 6, no. 13, pp. 2741-2748, 2006.

[20] S. Jamali. M.R.Javdan. H. Shateri and M. Ghorbani, "Load Flow Method for Distribution Network Design by Considering Committed Loads", Universities Power Engineering Conference, vol.41, no.3, pp. 856 - 860, Sept. 2006. 
[21] R. Singh, B. C. Pal, R. A. Jabr, and P. D. Lang, "Distribution system load flow using primal dual interior point method," in Proc. IEEE Power System Technology and IEEE Power India Conf., 5 pp., New Delhi, India, 12-15 Oct. 2008.

[22] S. Satyanarayana, T. Ramana, S. Sivanagaraju, and G.K. Rao, "An Efficient Load Flow Solution for Radial Distribution Network Including Voltage Dependent Load Models", Electric Power Comp. Syst., Vol. 35, No.5, pp. 539-551, 2007.

[23] K. Nagaraju, S. Sivanagaraju, T. Ramana and P.V.V. Prasad, "A Novel Load Flow Method for Radial Distribution Systems including Realistic Loads”, Electric Power Comp. Syst., Vol. 39, No.2, pp. 128-141, 2011.

[24] Ahmed R. AbulWafa, "A network-topology-based load flow for radial distribution networks with composite and exponential load”, Electrical Power System Research, Vol. 91, No. 4, pp. 37-43, 2012.

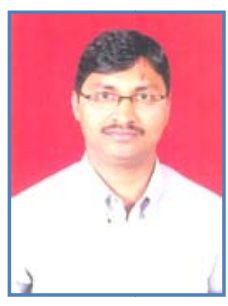

T. Ramana was born in Proddatur, Andhra Pradesh on July 04, 1978. He received the B.Tech. degree in electrical and electronics engineering from the JNT University, Hyderabad and the M.Tech degree in power and industrial drives from JNT University, Kakinada. He is currently pursuing the Ph.D. degree at the JNT University, Anantapur, Andhra Pradesh, India. Currently, he is working as Business Analyst in HP Global Soft Limited, Bangalore, Karnataka. He was an Assistant Professor with the Vignan's Engineering College, Vadlamudi, Andhra Pradesh, India. His research interests are Distribution System Planning, Power Quality, Reliability, Distributed Generation and Flexible AC Transmission Systems (FACTS). He has published more than 30 research papers in refereed journals and conferences proceedings. Mr. Ramana is Associate of Institute of Engineers (India), Life member of Indian Society for Technical Education.

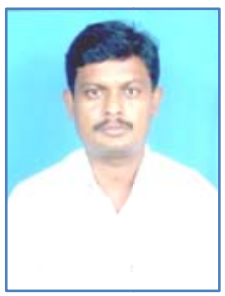

V. Ganesh was born in Jammalamadugu, Andhra Pradesh on June 15, 1974. He received the B.Tech. degree in electrical and electronics engineering from the JNT University, Hyderabad in 1998 and the M.Tech degree in power system operation and control from SV University, Tirupati and the Ph.D. degree in electrical engineering from JNT University, Anantapur in 2010. Currently, he is an Associate Professor and Head of the Department in Electrical and Electronics Engineering, JNTUCE, Pulivendula, Kadapa, Andhra pradesh. His research interests are Distribution System Planning, Power Quality, Reliability, Distributed Generation, Flexible AC Transmission Systems (FACTS) and Smart Grid. He has published more than 15 research papers in refereed journals and conferences proceedings. Mr. Ganesh is Life membership of System Society of India, Life membership of Indian Society for Technical Education.

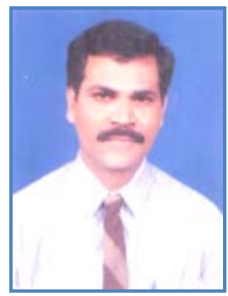

S. Sivanagaraju was born in Kadapa, Andhra Pradesh on July 01, 1970. He received the B.Tech. degree in electrical and electronics engineering from the Andhra University, Visakhapatnam in 1998, the M.Tech degree in Power Systems from IIT, Kharagpur in 2010 and the Ph.D. degree in Electrical Power System from JNT University, Hyderabad in 2004. Currently, he is Professor and Head of the Department in Electrical and Electronics Engineering in JNT University College of Engineering, Kakinada, Andhra Pradesh. He was an Associate Professor with the JNT University College of Engineering, Anantapur, Andhra Pradesh, India. His research interests are Distribution System Planning, Power Quality, Distributed Generation and Flexible AC Transmission Systems (FACTS). He has published more than 100 research papers in refereed journals and conferences proceedings. He received two national awards (Pandit Madan Mohan Malaviya memorial prize and Best paper prize award). 